\title{
Conductometric study of potassium chloride in ethylene glycol + water mixtures at different temperatures
}

\author{
Zdzisław Kinart ${ }^{1}$ and Renato Tomaš ${ }^{2, *}$ \\ ${ }^{1}$ Department of Physical Chemistry, Faculty of Chemistry, University of Lodz, 90-236 Lodz, \\ Pomorska 163/165, Poland \\ ${ }^{2}$ Department of Physical Chemistry, Faculty of Chemistry and Technology, University of Split, \\ Ruđera Boškovića 35, HR-21000 Split, Croatia \\ "E-mail: rtomas@ktf-split.hr
}

doi: $10.20964 / 2020.06 .91$

Received: 9 March 2020 / Accepted: 20 April 2020 / Published: 10 May 2020

\begin{abstract}
Molar conductivity of $\mathrm{KCl}$ solutions in ethylene glycol + water mixtures $\left(w_{\mathrm{EG}}=0.10,020,0.30\right.$, and $0.40)$ was measured at $T=(278.15,288.15,298.15$, and 308.15$) \mathrm{K}$. The values of limiting molar conductivity $\left(\Lambda^{\circ}\right)$, association constant $\left(K_{\mathrm{A}}\right)$ and distance parameter $(R)$ were calculated using the low concentration Chemical Model (lcCM). In this paper the values of Walden product $\left(\Lambda^{\mathrm{o}} \cdot \eta\right)$, as well as the standard thermodynamic quantities for the association reaction at $T=298.15 \mathrm{~K}$ were presented. Changes in these quantities as a function of changes in the composition of the mixed solvent have been discussed.
\end{abstract}

Keywords: potassium chloride, ethylene glycol + water mixtures, conductivity, thermodynamic quantities, Walden product, association distance.

\section{FULL TEXT}

(C) 2020 The Authors. Published by ESG (www.electrochemsci.org). This article is an open access article distributed under the terms and conditions of the Creative Commons Attribution license (http://creativecommons.org/licenses/by/4.0/). 